\title{
Patients taping staff
}

\author{
Matthew Stephenson
}

I would like to ralse lssues about tape-recorded interviews by woy of doscrtbing the recent admission to hosplial of a man who began recording staff and patients.

\section{Case report}

Mr $J$ is a 38-year old man who has had a number of admissions to psychiatric hospitals, all of which seemed to tide him over various crises. At different times he has been diagnosed as suffering from depresstve personality disorder and also manic depressive psychosis, depressed type. On review he fulfils the criterla more for someone with a personality disorder rather than a manic depressive disorder, whose variations in level of function relate to his drug and alcohol intake and environmental stresses. Biological symptoms have rarely been sustained and depressive symptoms and feelings of emptiness persist between periods of disturbed behaviour. His treatment has been characterised by marked ambivalence towards his carers so that it has not been possible to have ongoing therapeutic contact with him.

It is postulated that his personality difficulties resulted from his early family life when he was brought up by a physically and emotionally abusive father and a mother unable or unwilling to protect him from this. Despite his disturbed upbringing he attained 7 ' $O$ ' levels at school and trained as an electronics engineer.

His recent admission was precipitated by the birth to his girlfiriend of his first child. It seems that his wife became less able to look after him and he became depressed. Shortly after admission his symptoms of depression and anxiety diminished and he began to taperecord staff. The recording was not done with the consent of staff and had a threatening, controlling nature in that he professed to be collecting information with which to take legal action against staff. At times the recordings would be disguised and tapes were made of staff when they were unaware, at other times Mr $J$ approached staff with a recording machine in sight, saying that he was going to tape his dealings with staff.

For the staff concerned, it was possible to avoid major problems as he was thought to be well enough not to merit in-patient treatment by the time the threats of taping were percetved as problematic. Subsequently he was discharged. It does, however, raise questions about tape recording interviews and interactions in general.

\section{Comment}

It is helpful to look at medical notes from two perspectives: that of the doctor and that of the patient. For the doctor, notes prevent errors by allowing treatment to take place in a wellrecorded historical context. For the patient, s/ he may gain further insight into her/himself and her/his treatment. From the medico-legal perspective it allows the doctor to record good practice, for the patient it acts as a safeguard against bad practice.

Do patients recording their interactions with their carers fulfil the same function as do their own access to notes? I feel the answer is predominantly 'no'. Direct recording fails to take into account the carer's perspective which is exactly what the notes provide. When notes are read they may clarify points but only if taken in context. This contextual recording cannot occur from simple, unedited recordings. Also, erratic recordings may reflect emotional issues and transactions that could be hidden by notes recorded on paper, but could only be helpful if the process was coherent, comprehensive and did not influence the nature of the interactions themselves, something which tape-recording does far more than attempts to record on paper.

A further problem exists in the potential for parties in control of the recording not simply to be selective about what is recorded but to actively edit the tapes. The possibility for standard recordings to be made on the same 
machines and in the same place may enable some of these problems to be avoided (as in police work) yet this could provide only a fraction of the total picture available to staff. The current legal position is that there is no bar to patients surreptitiously or otherwise making tape-recordings. There is no recognition of a right to privacy which might be invoked by concerned staff.

Tape-recordings are admissible in court per se but various factors will dictate whether or not a tape is admissible in a particular case. For instance, if the accuracy of the recording cannot be proven and the voices cannot be identified - a judge would be likely to view such evidence with caution. It is difficult to see how in general a judge could give greater weight to this than to medical records as the law now stands. There is little written on the subject, though Goldstein (1988, 1989) writes of the consequences of survelllance of a forensic examination. He cites arguments for and against surveillance but notes the lack of evidence to justify one position over the other.
Guidelines might be helpful to avoid medicolegal aspects of this issue obscuring the underlying dynamics of a person's treatment and would be in the interests of both staff and of patients.

\section{Acknowledgements}

I would like to thank Katherine Harnsworth (LLB Hons) for her legal advice and Dr Mark Potter for permission to publish the case study.

\section{References}

Goldstren, R. L. (1988) Consequences of survellance of the forensic poychiatric examination. American Journal of Psychiatry. 145. p 1243-1247.

- (1989) Patients surreptitious taping of forensic psychiatric examinations. American Joumal of Psychiatry, 148, p 279-280.

Matthew Stephenson, Clinical Research Fellow, St George's Hospital, Tooting, London SW17 OQT.

\begin{tabular}{|c||}
\hline $\begin{array}{c}\text { Defeat Depression Action Day } \\
\text { Wednesday 12 April 1995 }\end{array}$ \\
"SPEAKEASY \& GOOD FOR-TUNE" \\
present \\
A DYSPEPTIC DINNER ENTERTAINMENT \\
in aid of The Defeat Depression Campaign \\
"The Anatomy of Melancholy" (or 'Gone for a Burton') \\
A wry (and awry) contemplation of depression \\
through the ages (from Job to even jollier!) \\
in song, poetry, drama \& prose \\
Wednesday 12 April 1995 \\
7.45pm, at The Royal College of Psychiatrists, \\
17 Belgrave Square, London SW1X 8PG \\
Cost: $\notin 17.50$ (includes a substantial buffet supper) \\
Defeat \\
Dopression $\quad$ For further information contact Deborah Hart on 0171235 2351
\end{tabular}

